
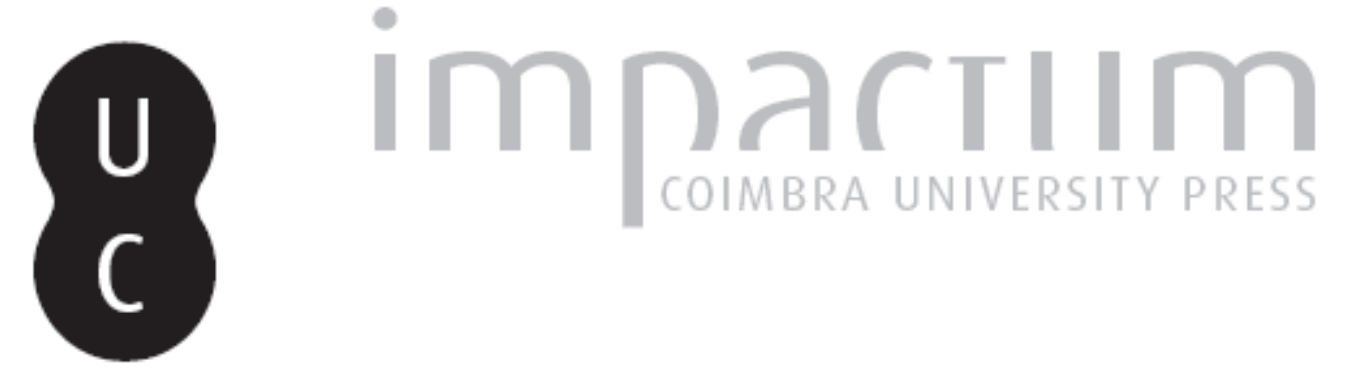

\title{
Cultura de risco e segurança coletiva no Brasil: a vulnerabilidade socioespacial a jusante de Itaipu binacional
}

\author{
Autor(es): $\quad$ Soriano, Érico; Valencio, Norma F. L S. \\ Publicado por: Associação Portuguesa de Riscos, Prevenção e Segurança \\ URL \\ persistente: \\ URI:http://hdl.handle.net/10316.2/36052 \\ DOI: \\ DOI:http://dx.doi.org/10.14195/1647-7723_18_9 \\ Accessed : $\quad$ 26-Apr-2023 16:20:29
}

A navegação consulta e descarregamento dos títulos inseridos nas Bibliotecas Digitais UC Digitalis, UC Pombalina e UC Impactum, pressupõem a aceitação plena e sem reservas dos Termos e Condições de Uso destas Bibliotecas Digitais, disponíveis em https://digitalis.uc.pt/pt-pt/termos.

Conforme exposto nos referidos Termos e Condições de Uso, o descarregamento de títulos de acesso restrito requer uma licença válida de autorização devendo o utilizador aceder ao(s) documento(s) a partir de um endereço de IP da instituição detentora da supramencionada licença.

Ao utilizador é apenas permitido o descarregamento para uso pessoal, pelo que o emprego do(s) título(s) descarregado(s) para outro fim, designadamente comercial, carece de autorização do respetivo autor ou editor da obra.

Na medida em que todas as obras da UC Digitalis se encontram protegidas pelo Código do Direito de Autor e Direitos Conexos e demais legislação aplicável, toda a cópia, parcial ou total, deste documento, nos casos em que é legalmente admitida, deverá conter ou fazer-se acompanhar por este aviso.

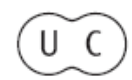




\section{territorium}

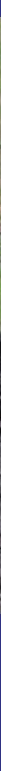

\section{Afirmar as Ciências Cindínicas}

Revista da Associação Portuguesa de Riscos, Prevenção e Segurança 


\section{A VULNERABILIDADE SOCIOESPACIAL A JUSANTE DE ITAIPU BINACIONAL*}

Érico Soriano

Escola de Engenharia de São Carlos, Universidade de São Paulo (USP)

Bolsista do CNPq

ericogeo@sc.usp.br

Profa. Dra. Norma F. L S. Valencio

Departamento de Sociologia da Universidade Federal de São Carlos (UFSCar) normaf@terra.com.br

\section{RESUMO}

Vivemos numa sociedade que se baseia numa cultura de risco, ou seja, em que a condição do risco não é aceita e/ou divulgada para a maior parte da população. Para corresponder a essa cultura do risco, emergiu uma cultura de segurança para lidar com os novos riscos surgidos por conta do progresso acaba por reger a normalidade da vida social moderna. Uma produção social de risco no Brasil é a produção de barragens, principalmente os Grandes Projetos Hidrelétricos. Este trabalho terá como base os riscos associados à UHE Itaipu Binacional e a vulnerabilidade das populações a jusante.

Palavras chave: risco, desastre, barragens, sociedade do risco, sistemas peritos.

\section{RESUMEN}

Cultura del riesgo y la seguridad colectiva en brasil: la vulnerabilidad intermedios Itaipú socioespatial- Vivimos en una sociedad que se basa en una cultura del riesgo, es decir, la condición en la que el riesgo no es aceptado y/o divulgación de la mayoría de la población. Para cumplir con esta cultura del riesgo, surgió uma cultura de seguridad para hacer frente a los nuevos riesgos que puedan presentarse en cuenta el progreso en definitiva gobierna la normalidad de la vida social moderna. Una producción social de riesgo en Brasil es la producción de las represas, especialmente en grandes proyectos hidroeléctricos. Este labor se basará en los riesgos asociados com HPP Itaipu Binacional y la vulnerabilidad de personas rio abajo.

Palabras clave: riesgo, desastre, barramentos, Sociedad del riesgo, los sistemas expertos.

\section{RÉSUMÉ}

Culture du risque et la sécurité collective au Brésil: la vulnérabilité socio spatiale Itaipu aval- Nous vivons dans une sociéte qui est basée sur une culture du risque, à savoir l'état dans lequel le risque n'est pas acceptée et/ou communiqués pour la majorité de la population. Pour répondre à cette culture du risque, a émergé une culture de la sécurité pour faire face aux nouveaux risques découlant du fait dês progrès em définitive, gouvernent La normalité de la vie sociale moderne. Une production sociale du risque au Brésil est la production des barrages, en particulier les grands projets hydroélectriques. Ce travail sáppuiera sur les risques liés à PHP Itaipu binationale et la vulnérabilité des personnes vivant val.

Most-clés: à risque, em cãs de catastrophe, les barrages, les systèmes de La Socétè dês risques par dês experts.

\section{ABSTRACT}

Culture of risk and collective security in Brazil: the vulnerability socioespatial downstream itaipu Binational - We live in a society that is based on a culture of risk, that the condition in which the risk is not accepted and/or disclosed for the majority of the population. To meet this risk culture, emerged a culture of safety to deal with the new risks arising on account of progress ultimately govern the normality of modern social life. A social production of risk in Brazil is the production of dams, especially large hydropower projects. This work will build on the risks associated with HPP Itaipu Binational and vulnerability of people downstream.

Keywords: risk, disaster, dams, Society of risk, expert systems.

* O texto deste artigo corresponde à comunicação apresentada ao II Congresso Internacional de Riscos e VI Encontro Nacional, tendo sido submetido para revisão em 31-05-2010, tendo sido aceite para publicação em 26-07-2010.

Este artigo é parte integrante da Revista Territorium, n. ${ }^{\circ} 18,2011$, ® RIscos, ISBN: 0872- 8941. 


\section{Introdução}

O risco é uma situação que sempre acompanha o homem em sua história, podendo ser de vários tipos e intensidades, dependendo das especificidades do local e da parcela da população que se analise. Pode ser a possibilidade de uma situação ameaçadora, como afirma R. Menescal et al. (2001, p.36), “A expressão "risco" pode referir-se à probabilidade de ocorrência de um evento adverso como também considerar de alguma forma os seus efeitos". Já Y. VeYret (2007, p. 30) considera que o risco é "a representação de um perigo ou álea (reais ou supostos) que afetam os alvos e ou constituem indicadores de vulnerabilidade". De acordo com a Secretaria Nacional de Defesa Civil (2009), 0 Risco é definido como a "probabilidade de ocorrência de um acidente ou evento adverso, relacionado com a intensidade dos danos ou perdas, resultantes dos mesmos." De acordo com A. GidDens (1991, p.42), "o que é visto como risco "aceitável" - a minimização do perigo - varia em diferentes contextos, mas é geralmente central na manutenção da confiança”.

Uma modalidade dos riscos é a possibilidade do colapso de barragens, principalmente os grandes barramentos das Usinas Hidrelétricas, característica presente no Brasil. As barragens são construídas com a intenção de formar um reservatório, seja para a deposição de algum material tóxico que deva ser isolado de determinado meio, seja para conservação de água para períodos de estiagem, assim como para o aproveitamento do potencial hidrelétrico.

Estes barramentos podem representar riscos para a população imediatamente a jusante destas construções, que se mostra em situação vulnerável. Esta relação entre as barragens e o risco mostra-se, na verdade, significativa em função do número de rompimentos recentes. Segundo R. Menescal (2005), apenas considerando o período de cinco anos, foram mais de 400 acidentes com barragens no Brasil, muitos associados à falta de manutenção das barragens ou ao completo abandono. Tendo como base a magnitude dos reservatórios de algumas hidrelétricas e a intensidade de danos associados a um eventual colapso estrutural de suas respectivas barragens, é possivel ter uma base dos riscos.

Os sistemas, no seu bojo, parecem bem ordenados e gerenciáveis pelas instituições que a eles produziram e se especializaram em mantê-los. Porém, a modernidade superpõe, de uma maneira complexa, muitos sistemas e é na interface destes sistemas que aparecem os problemas cuja natureza sinérgica não permite serem eficientemente gerenciados pelas instituições que representam e agem sobre o problema partitivamente. A sinergia de sistemas gera a necessidade de diálogo entre os peritos das instituições envolvidas, exige a imersão de novos peritos no tratamento do problema, com choques de representações sobre a questão, conflitos de procedimentos, tensões em novas relações de comando e controle que precisam ser estabelecidas entre os experts e técnicos envolvidos e, ainda, choques entre as aspirações e julgamentos da opinião pública para resolver as falhas, perdas e prejuízos havidos e aquilo que está sendo praticado. Enfim, uma cultura de segurança institucional está longe de garantir que o diálogo entre as partes envolvidas seja desprovido de tensões.

Um dos aspectos de insuficiência da cultura de segurança é a ausência de conhecimento e monitoramento sobre determinado fator de ameaça que permita atuação preventiva e/ou preparativa adequada. Assim, ocorre de certos eventos serem discursivamente assumidos pelas instituições de segurança como sendo "situações inesperadas", narrativa própria para não assumir a ineficiência institucional e cujas perdas, danos e prejuízos acabam ficando na conta de fatalidades. Como por exemplo, em relação ao terremoto ocorrido no Brasil em 2008 no semi-árido mineiro e o furacão Catarina, o primeiro desta categoria no Atlântico sul que se tem notícia, ocorrido em 2004. Não havia cultura de segurança sobre estes fenômenos. Da mesma forma, não havia mecanismos de prevenção e preparação eficientes por parte das autoridades. Estes exemplos ressaltam as limitações dos sistemas peritos, organizados para garantir a segurança da população. Dentre elas, destacam-se: as limitações relativas às dimensões da vulnerabilidade da população na área de impacto do evento, o que implicava na mescla de conhecimentos geográficos físicos e humanos, sociais, econômicos dentre outros; as limitações das séries estatísticas e disponibilização pública da informação sobre desastres relacionados ao referido evento e afins, dificultando alguma previsão mais abalizada.

Ao vivermos num ambiente de riscos para além daqueles que a cultura de segurança tem a capacidade resolver, ou seja, que estão além da condição de se tornar gerenciável, as incertezas pululam e tornamse incalculáveis. As medidas de segurança, até então socialmente aceitas, tornam-se inócuas o que, segundo J. Demajorovic (2003), se caracteriza como a emergência da sociedade de risco. Para G. CARAPINHEIRo (2002), os riscos só alcançam o debate político quando os efeitos de sua disseminação ganham visibilidade. Desta forma, a sociedade de risco converte-se na sociedade da catástrofe. Por outro lado, a idéia de viver-se em permanente estado de incerteza é suplantada por certos discursos e práticas, como o dos sistemas peritos da segurança, tais como os são os cursos de engenharia de segurança, as Cipas das indústrias dentre outros. Esta cultura da segurança tenta institucionalizar uma idéia de que a ameaça está sobre o controle através 
de procedimentos e/ou protocolos de como os agentes técnicos neutralizam estes riscos. Já Y. VEYRET (2007, p14) considera que o risco está em todas as partes de nossa sociedade, prevalecendo um sentimento de insegurança que se realimenta pelo "progresso da segurança, pelo desenvolvimento das ciências e de técnicas cada vez mais sofisticadas." Sociedade de risco é o conceito que U. BEck (1992) lança para analisar essa convivência com novos patamares de ameaças cotidianas na vida do cidadão comum, que vão da poluição atmosférica e hídrica, à de alimentação, trânsito e outras.

\section{A Vulnerabilidade}

A problemática deste trabalho é a vulnerabilidade social com correspondência a inserção territorial de populações a jusante de barragem devido às questões políticoinstitucionais que envolvem a cultura de segurança dos empreendimentos hidrelétricos. Desta forma, segue uma breve revisão de literatura sobre os principais conceitos ou categorias de análise para concluir os resultados de campo.

De acordo com a Secretaria Nacional de Defesa Civil (2009), a vulnerabilidade é a "probabilidade de uma determinada comunidade ou área geográfica ser afetada por uma ameaça ou risco potencial de desastre, estabelecida a partir de estudos técnicos."

Ainda segundo a Secretaria Nacional de Defesa Civil do Brasil (2009). "A Vulnerabilidade, como bem diz o conceito, está relacionada com o grau de defesa, resistência de edificações, sistemas, serviços, bem como as medidas de segurança, que são determinadas, executadas e realizadas pela população para reduzir os riscos ao ambiente e à população e, desta forma, evitar ou minimizar os desastres e as conseqüências ou danos dos mesmos".

Em relação à Vulnerabilidade, N. Adger, (2006, p. 269). "Vulnerability, by contrast, is usually portrayed in negative terms as the susceptibility to be harmed. The central idea of the often-cited IPCC definition (McCarthy et al., 2001) is that vulnerability is degree to which a system is susceptible to and is unable to cope with adverse effects (of climate change). In all formulations, the key parameters of vulnerability are the stress to which a system is exposed, its sensitivity, and its adaptive capacity. Thus, vulnerability research and resilience research have common elements of interest-the shocks and stresses experienced by the socialecological system, the response of the system, and the capacity for adaptive action. The points of convergence are more numerous and more fundamental than the points of divergence".

H. Acselrad (2006) considera que a noção de vulnerabilidade julga a susceptibilidade de um grupo a uma ameaça ou agravo. Os vulneráveis são definidos numa disputa entre três atores: Estado, movimentos sociais e pelo discurso do conhecimento perito. Já H. ToRres E E. MARQues (2001) consideram a vulnerabilidade social e ambiental a intensa concentração de indicadores negativos, que sugerem a indicação de pontos críticos em alguns espaços da periferia, considerando o território em que vivem populações de baixa renda e que sofrem riscos de ordem social como educação, saúde e urbanização, quanto ambientais, considerando a ausência de equipamentos urbanos básicos como o saneamento, coleta de lixo, etc. Da mesma forma, $\mathrm{H}$. Alves (2007) verificou e mediu a existência da associação entre piores condições socioeconômicas e sua maior exposição ao risco ambiental, sendo os mais pobres o grupo que apresenta maior vulnerabilidade social e ambiental.

Já para D. Hogan e E. Marandola (2004), o estudo dos natural hazards é uma tradição entre os geógrafos, que já trabalham com o termo desde a década de 20 . Ainda na linha geográfica, que relaciona os estudos da vulnerabilidade de uma forma complementar ao risco, S. CUTTER (1994) a denomina como a interação entre o risco existente em um determinado lugar e as características e o grau de exposição da população lá residente. Desta forma, considerando-se o espaço geográfico e os territórios. Já Y. VEYRET (2007), afirma que a sociedades modernas são muito vulneráveis, sendo mais sensíveis às "flutuações" meteorológicas do que as sociedades anteriores, principalmente, os efeitos sobre o turismo, no custo dos produtos agrícolas e no transporte.

N. Valencio (2005, p.18), considera a relação entre os desastres e a avaliação incorreta das ameaças e da compreensão incompleta da vulnerabilidade humana frente às mesmas. "Os barramentos de rios não são apenas incitadores de oportunidades múltiplas de uso da água; são, igualmente, fatores de perigo para a população à jusante, modificando o tipo de susceptibilidade em que a mesma se encontra no território".

\section{A Vulnerabilidade do Setor Elétrico Brasileiro}

Uma produção social de risco no Brasil é a produção de barragens, principalmente os Grandes Projetos Hidrelétricos. O setor hidrelétrico faz parte central da sociedade industrial porquanto fornece a base energética fundamental para o desenvolvimento dos demais segmentos urbano-industriais que replicam nesse país as condições materiais do que é simbolizado como ajuste à modernidade aspirada. Esta relação entre as barragens e o risco mostra-se significativa em função do elevado número de acidentes envolvendo estes empreendimentos. Estima-se que, apenas para o ano de 2004, mais de 300 barragens, tenham se rompido no país. 
No caso da UHE de Itaipu binacional, serão analisadas três variáveis de risco: os de Caráter Ecossistêmico, considerando principalmente a ação do mexilhão dourado na referida UHE; os Climáticos, uma vez que os cálculos estruturais são baseados em séries históricas de precipitação que se modificaram com as mudanças no clima; e, o de Terrorismo, considerando a presença de população islâmica na região da tríplice fronteira e sua suposta relação com a Rede internacional de Terrorismo. Seja qual fosse à cultura institucional de segurança, ela já não se verifica mais com a mesma certeza.

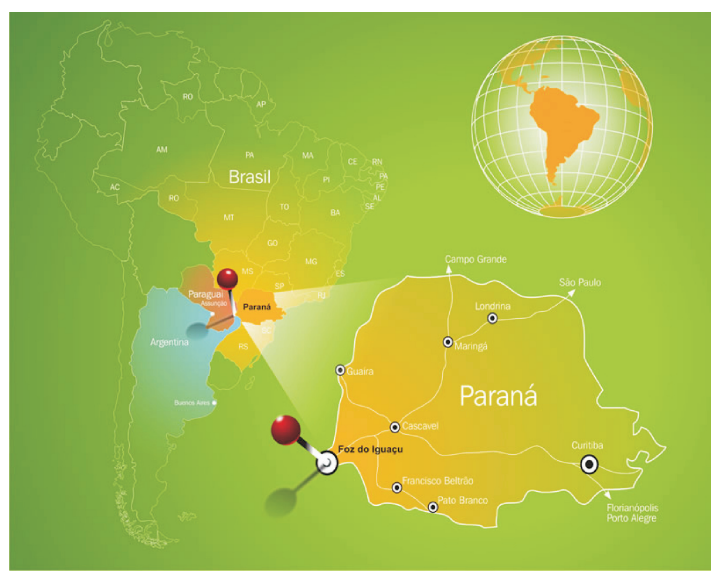

Fig. 1: Localização do Município de Foz do Iguaçu (Fonte: Prefeitura Municipal de Foz do Iguaçu, 2010).

O município de Foz do Iguaçu se localiza na Região sul do Brasil, no Estado do Paraná. Faz divisa com a represa da Itaipu Binacional ao Norte, alem da cidade de Puerto Iguazu na Argentina e Ciudad Del Este no Paraguai. Localiza-se imediatamente a jusante da barragem de Itaipu.

Registrava uma população de 319.189 habitantes em 2008, e uma densidade demográfica de 510,21 habkm2. População que apresentou crescimento demográfico positivo em função da construção da UHE, saltando de 35.000 habitantes em 1974, para 140.000 em 1979. Desta forma, constitui-se de uma população essencialmente migrante, que guardam grande relação com Itaipu binacional.

A UHE de Itaipu Binacional é uma usina hidrelétrica construída em conjunto com o Paraguai na fronteira entre os países. Localiza-se no Rio Paraná, na Bacia do Prata. O Reservatório da UHE apresenta 1350 km² de área inundada, entre os municípios de Foz do Iguaçu e Guaíra e atinge áreas de 16 municípios. A barragem registra um desnível de 120 metros de queda, para o funcionamento das turbinas. Além de 7.919 metros de extensão e 196 metros de altura. Atualmente, conta com as 20 unidades geradoras, sendo $18 \mathrm{em}$ atividade e 2 em manutenção. Registra uma produção média de 90 milhões de megawatts-hora (MWh) por ano, e é considerada a maior do mundo em produção.

\section{Os Riscos relacionados à UHE Itaipu Binacional}

Itaipu sempre foi forjada discursivamente, pela Eletrobrás e autoridades brasileiras, como um modelo de segurança. Porém, esta imagem de seguridade plena começa a se mostrar mais complexa com o passar dos anos. No modelo de segurança do caso Itaipu, alguns riscos emergiram recentemente, a saber:

\section{Riscos ambientais de caráter ecossistêmico}

Esse risco é representado por uma espécie invasora, o mexilhão dourado (Limnoperna fortunei), um molusco de água doce que é originário da China e que chegou ao Brasil em 1999, no Rio Grande do Sul, nas águas do Lago Guaíba. Esta espécie invasora se incrusta nas estruturas de ferro e de concreto das usinas, causando prejuízos através de entupimento de tubos de água para refrigeração das turbinas e elevam o tempo da manutenção dos equipamentos. 0 mexilhão é encontrado no lago da usina desde 2001.

A UHE de Itaipu já demonstra preocupação em relação ao mexilhão, afirmando que vem reduzindo progressivamente a quantidade de larvas deste molusco. De acordo com informação institucional de Itaipu, a ação voltada ao controle do mexilhão se iniciou em 2001, ano de aparecimento do organismo no reservatório da represa. 0 monitoramento da proliferação das larvas é realizado pela Divisão de Meio Ambiente do Reservatório da Itaipu. Outras medidas de controle são o aumento da vazão em encanamentos, injeções de hipoclorito em baixas concentrações, tintas anti-incrustantes e aplicação do gás ozônio.

Apesar da preocupação demonstrada pela administração de Itaipu, trata-se de um risco devido à magnitude do reservatório de Itaipu e pela dificuldade de eliminação desta espécie invasora, uma vez que os responsáveis pela segurança da binacional conseguem apenas controlar a quantidade de moluscos e não eliminá-los.

\section{Riscos climáticos}

O ritmo climático passou por alterações nas últimas décadas, sendo que a usina foi construída e preparada para suportar as condições hidrometeorológicas de um ritmo pretérito. Desta forma, ela não foi projetada e se mostra vulnerável aos novos regimes pluviométricos da região. 0 impacto que a mudança do regime de chuvas provoca nas UHEs e nas barragens é o da alteração no comportamento médio das vazões nas bacias dos rios, as quais serviam de base para o planejamento de barragens.

$\mathrm{Na}$ região Centro-Sul do país, as mudanças climáticas estão caracterizando o aumento das precipitações 
concentradas (C. Nobre, 2007). Conforme N. VAlencio et. al (2007), a cultura de segurança de cálculo estrutural das barragens é feita considerando as séries históricas de precipitação para se saber até quanto pode chover no período de pico. A alteração do regime das chuvas associada aos problemas de drenagem a montante tornam relativos os cálculos de segurança das obras civis e das barragens. 0 nível de segurança era próprio para época, mas não para hoje. M. Silva E A. Gueter (2003) constataram, através de análise da série temporal de vazão mensal dos rios na região central da América do Sul, que houve uma variação brusca verificada a partir da década de 1970. Segundo os autores, este aumento de vazão pode estar associado a mudanças climáticas ocorridas no Oceano Pacífico e ao aquecimento observado no Oceano Atlântico Sul.

Em relação ao estado do Paraná, eles concluíram que tem apresentado uma aceleração do ciclo hidrológico desde o início da década de 1970, o que provocou o aumento da frequiência de chuvas mais intensa e o aumento das vazões médias. Essa relação indica que um aumento de $30 \%$ nas chuvas provocaria um aumento de $40 \%$ na vazão dos rios. J. MARENGo E P. DiAs (2006) afirmam que as séries de vazões na Bacia do Rio Paraná apresentam um importante não estacionaridade entre períodos antes e depois da década de 1970, com um incremento de vazão que varia próximo a $30 \%$. Relacionado com as tendências de crescimento de chuva na Bacia, representa uma média cerca de $6 \%$ superior para o período de 1971 a 1990 comparado com o período de 1930-1970 (C. NoBRE 2003). Como pode ser observado no QuAdro I a seguir, considerando-se a média anual, houve um aumento de $36 \%$ da vazão entre os dois períodos analisados. Isso indica uma vazão muito superior àquela considerada durante a construção de Itaipu.

QUADRo I: Valores médios da vazão $\left(\mathrm{m}^{3} / \mathrm{s}\right)$ do rio Paraná, com destaque para a taxa de variação.

\begin{tabular}{|l|l|c|c|c|}
\hline \multirow{2}{*}{ Resolução } & $\begin{array}{l}\text { Atributo } \\
\text { estatístico }\end{array}$ & $\begin{array}{c}\text { Período } \\
(1941-1971)\end{array}$ & $\begin{array}{c}\text { Período } \\
(1972-2000)\end{array}$ & $\begin{array}{c}\text { Taxa de } \\
\text { Variação }\end{array}$ \\
\hline \multirow{2}{*}{ Anual } & Média & 325,9 & 442,5 & $+36 \%$ \\
\cline { 2 - 5 } & $\begin{array}{l}\text { Desvio } \\
\text { Padrão }\end{array}$ & 64,6 & 56,1 & $\ldots \ldots \ldots-\cdots$ \\
\hline
\end{tabular}

Fonte: Silva \& Gueter, 2003. Adaptado pelo autor

De acordo com Itaipu, as vazões afluentes ao reservatório apresentaram um crescimento positivo. A vazão média do rio Paraná, no período compreendido entre 1920 e 2002, foi de $9.845 \mathrm{~m}^{3} / \mathrm{s}$ e a vazão média nas últimas três décadas, período de 1983 a 2004, é de $11.766 \mathrm{~m}^{3} / \mathrm{s}$. Para a empresa, esse volume não se justifica apenas pela maior pluviosidade na Bacia do Rio Paraná. Justifica-se, também, pelo escoamento da bacia de drenagem, a montante de Itaipu, que registra outro volume em função dos usos e ocupação do solo inadequados nos contornos da represa como: impermeabilização do solo como conseqüência da urbanização, agricultura, destruição da mata ciliar, etc. J. Marengo e M. Valverde (2007) afirmam que as referidas modificações físicas na bacia de drenagem de Itaipu estão incrementando os valores das vazões do rio Paraná em Itaipu, representando um aumento de $28 \%$ no fluxo médio deste rio. Além disso, o regime pluviométrico na região é fortemente afetado pela ação do El Niño, que tende a aumentar a amplitude de precipitação em toda a área do vale do rio Paraná.

Curiosamente, estes novos riscos às obras civis, derivado da modernização do território à montante, são conseqüência de uma concepção de desenvolvimento, no geral, predatório, que os Grandes Projetos de Investimento, assim como denomina C. VAINER (2007a; 2007b), ensejou na macro-escala do país.

Itaipu faz uma estimativa do volume de água que atinge o reservatório utilizando dados hidrológicos e meteorológicos coletados, além de modelos matemáticos. Acompanham-se os rios de interesse em termos de chuva, vazão e nível da água para verificar a previsão de afluências e ajustar a operação da usina corretamente. Porém, face às mudanças climáticas e as alterações nas séries históricas de precipitação, estas medidas devem ser muito cuidadosas e o risco é uma constante.

Os engenheiros e planejadores da UHE de Itaipu tiveram como base técnica um cálculo decamilenar para basear sua política de segurança, fundamentada em cálculos estatísticos. Porém, devido à insuficiência de dados estatísticos no Brasil, principalmente no que concerne a restrita série de dados históricos das estações meteorológicas; as mudanças climáticas, quando somadas a outros fenômenos meteorológicos casuais como o El Niño, ou imprevisíveis como os furacões; e as mudanças no uso do solo, podem proporcionar um volume de água acima do esperado no represamento da UHE, o que pode aumentar o grau de incerteza a capacidade de gerenciamento da usina.

Segundo Y. Veyret e N. Richemond (2007, p.37), "Freqüentemente, os números não passam de indicadores qualitativos, estabelecidos visando à realização de comparações... O valor quantificado tranqüiliza; ele é percebido, em muitos casos, como justo, certo e, até mesmo indiscutível, fato que contribui para fazer crescer a incompreensão e a dúvida da população quando esse valor é questionado pelos fatos".

Trata-se de um sistema de objetos técnicos que reordena os outros objetos ao redor, inclusive o micro clima municipal. Desta forma, Itaipu pode ser considerada uma expressão da sociedade de riscos de U. BECK (1992), uma vez que alia a alta produtividade energética aos riscos. Isto aliado a fatores 
antropogênicos que proporcionam uma modificação em macro-escala, especialmente no clima. Ambos juntos aumentam a vulnerabilidade.

\section{Risco de ações terroristas}

A tríplice fronteira é reconhecida internacionalmente como uma das regiões mais complexas da América do Sul. O município de Foz de Iguaçu é uma área de colonização tradicionalmente árabe e de crença muçulmana, considerada a maior concentração desta população no Brasil depois do município de São Paulo. Após o atentado terrorista ocorrido no World Trade Center em 11 de setembro de 2001, em Nova lorque nos EUA, aventouse que segmentos dessa população estariam, de alguma forma, envolvidos na Rede Internacional de Terrorismo e a imprensa inclusive noticiou que ali se procurava células da Al Qaeda. De acordo com M. BARTOLomè (2003, p. 23), "Considerados em conjunto, pode-se dizer que $90 \%$ da comunidade árabe que mora em Foz e em Ciudad Del Este é de origem libanesa e seus membros têm parentes no Vale do Bekaa, no Líbano, epicentro da organização Hezbolah. Parte dessa comunidade árabe admite que tenha enviado dinheiro para os seus parentes no Oriente Médio, embora neguem que essa verba seja para apoiar o terrorismo".

Ainda de acordo com o autor, "Em novembro de 1995, a Polícia Federal do Brasil descobriu que na comunidade árabe de Foz se encontrava o libanês Marwan Al Safadi, perito em explosivos, considerado participante do atentado contra o edifício do World Trade Center em Nova York (EUA) em 1993".

O embaixador Francis Taylor, coordenador de contraterrorismo do Departamento de Estado, afirmou que a região é a mais problemática do hemisfério quanto a atividades de terroristas islâmicos (M. BARTOLOMĖ, 2003).

Ressalta-se que para esta população de origem muçulmana, estas especulações midiáticas criam o risco de estigmatizar estas populações. Mesmo considerando o fato de que as investigações não as incriminem, a mídia já tornou aquelas famílias alvos de uma suspeição pública.

De acordo com C. CASTRo (2007, p 226) “A melhor situação financeira dos muçulmanos no Brasil os livra do estigma de "ameaça econômica imigrante" encontrada na Europa, mas não os livra do anti-Muslimism do tipo estratégico disseminado pela mídia norte-americana". De forma complementar, a autora supra (2007, p.123) afirma que "uma visão que a sociedade como um todo tem da minoria pode direcionar sua autopercepção. Um exemplo simples desta afirmação é oferecido pela associação entre Islã e terrorismo tão presente na mídia e imaginário ocidentais. Um muçulmano ao falar sobre si e/ou sua religião no Brasil, assim como no Ocidente em geral, costuma enfatizar não ser terrorista. A preocupação em esclarecer este equívoco é extremamente comum, para não dizer onipresente".

Este trabalho não sugere esta relação, apenas leva este risco em consideração.

Este risco também foi considerado por Itaipu, considerando que após o ataque de 11 de setembro, fechou suas portas para a visitação turística pela primeira vez em sua história. Foi reaberta para visitação apenas no mês de outubro, com um esquema de segurança por parte de órgãos federais de defesa e de segurança, como a Polícia Federal e a Agência Brasileira de Inteligência.

De conhecimento público, só houve um encontro para se pensar nos riscos contemporâneos e na vulnerabilidade regional. Frente a um novo contexto, temos um Estado brasileiro pensando na vulnerabilidade da região. Será que tudo isso tem uma efetividade?

\section{Risco energético e da segurança nacional}

Itaipu é responsável por, aproximadamente, 19\% da energia elétrica de fonte hidráulica consumida no Brasil. Um colapso na barragem da UHE representaria uma crise na transmissão de energia no país.

Deve-se considerar a ineficiência do modelo energético nacional para a obtenção de energia elétrica através de sua matriz hídrica, com uma grande dependência do potencial hidrelétrico brasileiro. Pode-se afirmar que o Brasil registra um aproveitamento ineficiente em relação ao seu potencial e em relação às questões socioambientais subconsideradas durante a construção destes empreendimentos. I. SACHS (1994) indica que a capacidade de geração de energia, já instalada no país, é sub-explorada devido à falta de investimentos na manutenção e instalação de UHEs. Considera também que a maior parcela do potencial se encontra em pequenas centrais hidrelétricas, o que não condiz com a política atual de construção de grandes empreendimentos hídricos.

Para R. CostA (2007), o apagão ocorrido em 2001 e o conseqüente racionamento fazem da propaganda da Eletrobrás uma tática de terror, criando-se uma situação de crise energética que só seria resolvido com a construção de hidrelétricas, e quem se opor a estes empreendimentos é considerado atrasado, antiprogressista, etc.

Esta psicoesfera perversa da construção de megaprojetos hidrelétricos se dá em função das pressões do grande capital, interesses estes aliados aos do Governo brasileiro que, como já foi dito, vem se caracterizando por um novo modelo desenvolvimentista, vislumbrando mais uma vez a oportunidade de o país se tornar uma potência econômica. 
Itaipu apresenta o risco de ter a vida útil de seu reservatório reduzida, em função da poluição dos rios que formam a da bacia do rio Paraná e, como já foi dito, pela mudança no uso do solo em seu entorno. A concentração de sedimentos e de poluição pode representar riscos de danos mecânicos na UHE.

Desta forma, esta limitação na produção de energia se configura num risco em função da elevação nos padrões de consumo e com o crescimento da economia. Como exemplo, pode-se considerar o aumento do consumo provocado pelos aparelhos televisivos digitais, que apresentam um consumo energético superior ao modelo televisivo anterior. De acordo com o Conselho de Defesa de Recursos Naturais dos Estados Unidos, devido ao processo de conversão para o modelo digital estima-se que, naquele país, o consumo energético dos televisores chegará a 70 bilhões de kWh por ano, o que corresponde a números $50 \%$ superiores que os atuais. No caso brasileiro, onde o sistema HDTV é uma tecnologia ainda incipiente e em crescimento, o Brasil precisará produzir uma grande quantidade de energia apenas para suprir esta nova necessidade. Desta forma, aumentamse os riscos em função da produção e distribuição de uma quantidade maior de energia, provocados por uma necessidade criada em função de uma nova tecnologia que representa um consumo maior.

\section{Conflito Socioambiental numa escala Supranacional}

Outra questão significativa de região, que guarda relação com a Geopolítica, é o risco nas relações diplomáticas brasileiras no caso de um desastre na barragem de Itaipu.

Um colapso de barragem na referida represa faria com que a massa de água seguisse seu curso natural, atingindo o desnível da UHE e formando uma onda que atingiria diretamente áreas de Foz do Iguaçu e Ciudad del Este, no Paraguai. A corrente de água seguiria pela Bacia do Paraná e o seu volume excedente poderia proporcionar o rompimento da UHE de Yaciretá, na fronteira entre o Paraguai e a Argentina, cuja jusante é uma grande planície alagável, permitindo atingir diretamente áreas da Argentina, o que incluiria a capital Buenos Aires.

Devido a este risco, foi assinado o Acordo Tripartite entre Brasil, Paraguai e Argentina, em 19 de outubro de 1979, estabelecendo os níveis de água do rio Paraná e as variações permitidas para as usinas localizadas na bacia comum aos três países. Neste sentido, ao mesmo tempo em que a barragem pode ser colapsada num ato de terrorismo ou no caso de guerra, fazendo colapsar o sistema nacional de eletricidade, pode causar grandes desastres a jusante. Considerando a significância desta questão, pode-se destacar a realização da Primeira Reunião das Defesas Civis da Bacia do Prata.
Outra questão diplomática é a indisposição do governo do Paraguai acerca dos valores que o Brasil paga pela energia produzida pela Itaipu. O governo paraguaio quer rediscutir o Tratado de Itaipu, de 1973, no qual se firmou que o Brasil e o Paraguai têm direito a $50 \%$ da eletricidade gerada e que a energia não utilizada deve ser vendida necessariamente ao sócio, a um preço fixo. Desta forma, quer aumentar os valores que o Brasil paga pela energia da binacional assim como o perdão da dívida referente à obra da UHE, concluída em 1984. De acordo com o proposto pelo governo paraguaio, eles assumiriam uma dívida de US\$600 milhões, enquanto o Brasil ficaria com US\$19 bilhões. 0 governo paraguaio ameaça vender o excedente de sua produção, quase metade do total produzido pela UHE, para outros países.

Trata-se de uma questão geopolítica e diplomática, uma vez que a área das bacias e sub-bacias hidrográficas não respeita os limites territoriais criados politicamente entre os Estados. Em muitos casos, são rios de grande vazão que servem como instrumentos para divisa dos países, as fronteiras. 0 caso de Itaipu teve como uma de suas justificativas a definição da última fronteira brasileira que ainda não se encontrava devidamente delimitada. Desta forma, como alguns rios são internacionais abastecendo a vários países, o aproveitamento do seu potencial hidrelétrico deve ser feito de forma cuidadosa, pois pode: modificar a quantidade de vazão dos rios, reduzindo o volume de água de algumas regiões; comprometer a biodiversidade, e, para o que mais interessa a este trabalho, pode significar um risco para os países a jusante da barragem.

Considerando-se a questão fronteiriça, destaca-se o caso recente da construção das UHEs de Santo Antonio e de Jirau, que forma o complexo hidrelétrico do rio Madeira, cuja concessionária supostamente afirma que a área prevista para a bacia no Estudo de Impacto Ambiental poderia, supostamente, inundar áreas da Bolívia.

Segundo Y. VeYRet (2007, p18), “Construir o risco para geri-lo implica fazê-lo no quadro agora onipresente do desenvolvimento sustentável. O debate internacional passou de uma visão que opunha o desenvolvimento e a proteção da natureza para uma visão que tenta conciliar o desenvolvimento, gestão dos riscos e sustentabilidade por meio de normas de governança que freqüentemente ainda estão por ser definidas".

Tendo como base estes riscos e considerando os novos em relação ao contexto de inauguração do empreendimento, vários questionamentos podem ser feitos para que a sociedade de risco - isto é, produtora desse fator de ameaça - não se concretize numa sociedade de catástrofe. Dois conjuntos de questionamentos, centrais para esse estudo, são os seguintes: 
a) em que medida a cultura de segurança institucional e a confiança pública (das populações à jusante) nessa cultura, se coadunam? Quais as semelhanças e distinções em ambas? Quais as crenças e incertezas existentes nas narrativas desse par de opostos (o ente gerador do fator de ameaça e o ente em imediata vulnerabilidade?)

b) partindo da hipótese da ocorrência de algum evento que leve ao colapso das obras civis de Itaipu - em especial, relacionados aos riscos acima -, perguntase se estariam porventura coadunadas as medidas de emergência prognosticadas pelas instituições peritas e as esperadas pela população vulnerável para proceder à redução de riscos à vida e ao patrimônio ou estaremos diante de um novo cenário a ser chamado de fatalidade?

\section{Procedimentos metodológicos}

A etapa empírica desta pesquisa se desenvolveu através da análise das representações sociais das impressões da população residente no município de Foz do Iguaçu, localizado imediatamente a jusante da Usina Hidrelétrica de Itaipu. Desta forma, foram utilizados procedimentos técnicas de pesquisa qualitativa, como a observação não participante e de coleta de relatos orais por meio de roteiro sucinto de entrevista.

Foram realizadas entrevistas piloto com residentes em Foz do Iguaçu com a finalidade de se constatar a sua percepção e seu imaginário acerca dos riscos da UHE. A entrevista foi realizada em 10 bairros do município de Foz do Iguaçu, utilizando o método de pesquisa survey.

As entrevistas permitiram a constatação de que a população não se encontra preparada para o caso da ocorrência de algum problema na barragem. Não se observou nenhum contato entre órgãos de segurança do município e nem da referida empresa com a população de Foz do Iguaçu.

74,3\% dos entrevistados acreditam na possibilidade do rompimento da barragem da UHE em função do aumento do volume de água do reservatório, devido às constantes chuvas em várias regiões do Brasil. Mais de $20 \%$ acreditam que um rompimento seria possível através de um atentado terrorista. Destaca-se que, após os Atentados de 11 de Setembro, aventou-se a possibilidade de um atentado em Itaipu.

Já $82 \%$ dos entrevistados acreditam que um colapso na UHE representaria a inundação da totalidade de Foz do Iguaçu, em função do volume de água do reservatório.

Outra questão que se associa às Mudanças Climáticas e a participação da Itaipu binacional é a influência
QUADRO II: Principais variáveis de campo.

\begin{tabular}{|l|l|}
\hline Principais Variáveis de campo & $\begin{array}{l}\text { Percentual de } \\
\text { respostas }\end{array}$ \\
\hline $\begin{array}{l}\text { Existe algum contato entre } \\
\text { representantes da Defesa Civil com } \\
\text { membros da comunidade }\end{array}$ & $100 \%$ Não \\
\hline $\begin{array}{l}\text { Alguma autoridade já dialogou com } \\
\text { a comunidade sobre os riscos da } \\
\text { barragem }\end{array}$ & $100 \%$ Não \\
\hline $\begin{array}{l}\text { Existe algum plano de contingencia } \\
\text { para uma situação emergencial, tanto } \\
\text { por parte da defesa civil quanto pela } \\
\text { empresa }\end{array}$ & $100 \%$ Não \\
\hline $\begin{array}{l}\text { Você acredita que a barragem pode } \\
\text { romper }\end{array}$ & $\begin{array}{l}74,3 \% \text { acreditam } \\
\text { que sim. }\end{array}$ \\
\hline $\begin{array}{l}\text { Que áreas de Foz do Iguaçu seriam } \\
\text { afetadas com um eventual colapso }\end{array}$ & $\begin{array}{l}82 \% \text { acreditam } \\
\text { em inundação } \\
\text { total }\end{array}$ \\
\hline
\end{tabular}

da represa na localidade, ou seja, as modificações no micro-clima da região, em especial para o município de Foz do Iguaçu. De acordo com estudos da própria binacional, o lago é responsável pela modificação dos regimes dos ventos e de níveis de temperatura do ar, umidade, evaporação e radiação. Estas modificações foram prejudicais a agricultura da região, uma vez que provocaram o aquecimento do solo, déficit hídrico e redução da produtividade. Os produtores estão cobrando indenizações na justiça, no que compete aos prejuízos sofridos na produção nos últimos 20 anos. Trata-se de uma indenização estimada em mais de 2 bilhões de reais.

Nas entrevistas a modificação do microclima provocada pelo lago não pode ser constatada, uma vez que a população de Foz anterior ao lago era $90 \%$ menor do que a de hoje, e, cresceu maior parte dos entrevistados ou não era nascida, ou não residia em Foz antes da construção do lago. Apesar da ausência de comparação histórica, a maior parte dos entrevistados considera que o calor excessivo do município, que pode atingir os 45 graus, pode sim ter alguma relação com a represa.

\section{Conclusão}

Foi possível constatar que a população do município de Foz do Iguaçu guarda preocupação constante em relação à barragem devido ao volume de chuvas e a quantidade de água do rio Paraná. Isto permite observar que a confiança da população em relação à capacidade técnica e de segurança da empresa não se coaduna com o discurso institucional da empresa. È possível observar a incerteza em relação à estrutura da barragem o medo da população em relação a um eventual colapso. 
Apesar deste sentimento de insegurança e de vulnerabilidade, não se observa um mínimo de informação acerca de medidas emergenciais e de prevenção para a população do município, tanto por parte da empresa, quanto por parte dos órgãos de defesa e segurança pública. Existem os planos emergenciais, embora estejam restritos apenas as esferas de segurança pública, sem um dialogo ou uma preparação com a população que possa vir a ser afetada. O problema consiste na ausência de um diálogo e de uma preparação entre as Instituições que proporcionam o risco, os sistemas peritos e a população. 0 reconhecimento do risco se faz necessário para que ajam as medidas preventivas necessárias. Sem o reconhecimento público e discussão colectiva sobre os riscos tudo se passa, nas práticas institucionais, como se a população de Foz do Iguaçu não fosse vulnerável, não tivesse com o que se preocupar, incitando-a a esconder os seus medos, dentre eles, o de alimentar oculto receio e estigmatização dos grupos islâmicos locais.

A Usina de Itaipu apresenta um rigoroso sistema de controle e monitoramento. Porém, nenhuma obra de engenharia apresenta risco zero. O problema está no despreparo da população no que tange aos planos de emergência, o que corresponde a uma face irresponsável da cultura nacional, baseada numa sociedade de risco e não de segurança. Um plano emergencial, baseado numa concepção de segurança observada numa modernidade reflexiva, não seria um agente causador de pânico e medo para a população, até porque o medo já está presente na maior parte da população do local. Ações como esta poderiam evitar que um acidente em Itaipu se tornasse um desastre de grandes proporções em Foz do Iguaçu e outros municípios a jusante.

\section{Referências bibliográficas}

Acselrad, Henry. (2006) - Vulnerabilidade ambiental, processos e relações. In: Comunicação ao II Encontro Nacional de Produtores e Usuários de Informações Sociais, Econômicas e Territoriais, FIBGE, Rio de Janeiro.

AdGER, Neil. (2006) - "Vulnerability". Global Environmental Change. London, n. ${ }^{\circ} 16$, p.268281.

AlmeidA, Antonio Betamio (1999) - "Riscos A Jusante de Barragens e Legislação", in Jornada Técnica sobre Legislação sobre Segurança de Barragens, Projecto NATO PO-Floodrisk Management, LNEC, Lisboa.

Alves, Humberto Prates da Fonseca (2006) "Vulnerabilidade socioambiental na metrópole paulistana: uma análise sociodemográfica das situações de sobreposição espacial de problemas e riscos sociais e ambientais". Revista Brasileira de Estudos Populacionais, São Paulo, v.23, n.1, p.43-59.

BECK, Ulrich. (1992) - Risk Society: towards a new modernity. Sage, London.

BARTOlomé, Mariano César (2003) - "A Tríplice Fronteira: Principal foco de insegurança no cone sulamericano". Military Review, v.83.

CARAPINheIro, Graça. (2002) - A Globalização do risco social. In: SANTOS, B. S. (org.) A Globalização $e$ as Ciências Sociais. Cortez, São Paulo.

Castro, Cristina Maria de. (2007) - A Construção de Identidades Muçulmanas no Brasil: um estudo das comunidades sunitas da cidade de Campinas e do bairro paulistano do Brás. Tese (Doutorado). Universidade Federal de São Carlos, São Carlos.

CostA, Reinaldo Corrêa. (2007) - Hidroelétricas e Territorialização de Impactos: Bases Analíticas. Trabalho apresentado no I Encuentro Latinoamericano de Ciências Sociales y Represas, e II Encontro Brasileiro de Ciências Sociais e Barragens. Salvador.

CutTer, Susan L. (1996) - "Vulnerability to environmental hazards". Progress in Human Geography, v.20, n.4, p.529-539.

Demajorovic, Jacques. (2003) - Sociedade de risco e responsabilidade socioambiental. Perspectivas para a educação corporativa. Editora SENAC, São Paulo.

GIDDENS, Anthony (1991) - As Conseqüências da Modernidade. UNESP, São Paulo.

Hogan, Daniel J. e Marandola JR, Eduardo. (2005) - “Towards an interdisciplinary conceptualization of vulnerability. Population", Space and Place. n. ${ }^{\circ} 11$, p.455-471.

ITAIPU BINACIONAL - http://www.itaipu.gov.br Acessado em: 13/07/2008

Marengo, José Antonio Orsini e Dias, Pedro L. da Silva (2006) - Mudanças climáticas globais e seus impactos nos recursos hídricos. In: REBOUÇAS, A. da C.; BRAGA, B; TUNDISI, J. G. Águas Doces no Brasil: Capital Ecológico, Uso e Conservação. Escrituras Editora, São Paulo.

Marengo, José Antonio Orsini e Valverde, Maria C. (2007)"Caracterização do clima no século xx e Cenário de Mudanças de clima para o Brasil no século XX usando os modelos do IPCC-AR4". Revista Multiciência, n. ${ }^{\circ} .8$, pp.1-24. 
Marengo, José Antonio Orsini (2008) - “Água e Mudanças Climáticas”. Estudos Avançados, vol.22, n. ${ }^{\circ} .63$, pp. $1-14$.

Menescal, Rogério de Abreu e Cruz, Paulo Teixeira e Carvalho, Roneí Vieira de e Fontenelle, Alexandre de Souza e Oliveira, Sandra Keila Freitas de. (2001) - Uma Metodologia para Avaliação do Potencial de Risco em Barragens do Semiárido. In: XXIV Seminário Nacional de Grandes Barragens, 2001, Fortaleza-CE. Anais do XXIV Seminário Nacional de Grandes Barragens. Rio de Janeiro.

Menescal, Rogério de A. (org). (2005) - A Segurança de Barragens e a Gestão de Recursos Hídricos no Brasil. Proágua, Brasília.

Ometto, Jean Pierre e Nobre, Carlos Afonso. Mudanças Ambientais Globais: Desafios para o futuro. Regional Office of the International Geosphere- Biosphere Programme (IGBP). Instituto Nacional de Pesquisas Espaciais- INPE. Disponível em: http://www.mudancasglobais. com.br/mudancasglobais/releases/Mudancas_ ambientais.pdf.

SACHS, Ignacy (1994). Estratégias de transição para o século XXI. In: BURXZTYN, M. (org).Para pensar o desenvolvimento sustentável. Brasiliense, São Paulo.

Secretaria nacional de defesa civil. Política Nacional de Defesa Civil. Brasília, p.97, jan.1995. Disponível em: <http://www.defesacivil.gov.br.> Acesso em 14 de julho de 2008.

Silva, Maria Eliseira Siqueira e Guetter, Alexandre K. (2003) - "Mudanças climáticas regionais observadas no estado do Paraná”. Terra Livre, vol.1, n. ${ }^{\circ} 20$, pp. 111-126.

Torres, Haroldo da Gama e Marques, Eduardo. (2004) "Políticas sociais e território: uma abordagem metropolitana”. São Paulo em perspectiva. São Paulo, v. 18, n. ${ }^{\circ} 4$, p.28-38.

VAINER, Carlos (2007) - “Recursos Hidráulicos: questões sociais e ambientais”. Estudos Avançados, v. 21, p. $119-138$

Valencio, Norma Felicidade Lopes da Silva (2005) - Dimensões psicossociais e políticoinstitucionais do desastre de Camará. (PB) limitações da resposta da Defesa Civil frente ao rompimento de barragens. In: I Encontro de Ciências Sociais e Barragens, 2005, Rio de Janeiro. Anais do I Encontro de Ciências Sociais e Barragens. Rio de Janeiro: IPPUR/ UFRJ. CD-ROM, p.1-20.

Valencio, Norma Felicidade Lopes da Silva (2007) - O Sistema Nacional de Defesa Civil (SINDEC) diante das Mudanças Climáticas: desafios e limitações da estrutura e dinâmica institucional. In: Encontro Nacional da Associação Brasileira de Estudos de Defesa, 1, 2007, São Carlos. Anais. São Carlos: ABED, p. 1-15.

Veyret, Yvete e Richemond, Nancy Meschinet de. (2007) Definições e vulnerabilidades do risco. In: VEYRET, Yvete. (org). Os riscos: o homem como agressor e vítima do meio ambiente. Contexto, São Paulo.

VEYRET, Yvete. (org). (2007) - Os riscos: o homem como agressor e vítima do meio ambiente. Contexto, São Paulo. 